\title{
Optimization of Agnelina Joint Automotive Logistics of Transport and Line
}

\author{
Shi Xin \\ International trade Department \\ Shengyang Aerospace University \\ Shengyang China
}

\begin{abstract}
With the continuous development of the urban economy, the growing demand for automobiles and the automotive logistics demand also will continue to grow. The vehicle logistics is an important part of automotive transportation and distribution logistics, Mode of transport and the pros and cons of lines to choose to have a major impact on the operational efficiency and reduce transportation costs of the entire automotive logistics system. Therefore, in order to meet the rapid growth in demand of automotive logistics, and response to the national green economy and the direction of development of the logistics industry major policies. It is very necessary to optimize the vehicle logistics of transport.In this paper, followed by the national logistics development direction of the latest policy, and automotive logistics of transport and route optimization for large research direction, Angelina Joint Logistics company mode of transport and route optimization problems met in reality, for example, The vehicle logistics of transport problems from the road on the distribution and water distribution discuss optimize the two aspects of the mode of transport and transport routes.
\end{abstract}

\section{Keyword-Automotive Logistics; Select; Optimization}

\section{INTRODUCTION}

In recent years, with the rapid development of China' s economy and general improvement of people's living standards, the auto industry in China has entered a rapid development period. $25 \%-35 \%$ 。 Since China' s entry into WTO, the explosive growth has continued with the automobile market in china. The past ten years is an unprecedented history of the high-speed development, and the total vehicle growth rate has always maintained from $25 \%$ to $35 \%$.

With continuous high-speed development of China's auto market, demand on China's auto logistics market greatly increases. In view of the hot operation and continuing on logistics demand in the auto logistics industry in China, there are many items of low-level service and few high-end and differentiation service, the domestic automobile production heads are beyond the area layout of production base, there is high requirement on the regional auto logistics coordination, route optimization and vehicle transportation capacity; the private consumption has become the theme of automobile demand structure, and the required is of timely and fine product supply.

\section{DEFINITION AND DEVELOPMENT SitUATION OF AUTOMOBILE LOGISTICS}

Automobile logistics refers to transportation ways including highways, railways, waterways or jointed transportation to view parts suppliers at the raw material supply area, vehicle assemblers at the origin area and vehicle distributors at the consumption area and to transport vehicle parts, car finished goods to the car production base and distribution network points.

An efficient, rational and modern logistics system is the necessary condition for the rapid development of the automobile industry. But because of historical reasons and system issues, the automobile logistics in China is still at an early stage of development, and the overall level still has a long way to go compared with the developed countries. At present, traditional operation including transportation and warehousing has a large proportion in the service functions given automobile logistics industry in China, and the $85 \%$ of logistics service revenue comes from these basic services.

\section{ANALYSIS OF AGNELINA UNITED LOGISTICS CASES}

\section{A. Case Description}

SAIC is the outstanding representative of the domestic automobile manufacturing enterprises. At the same time, it is the largest car producers and passenger car manufacturer with the largest sales volume. Agnelina Automobile Logistics Co. Ltd is the whole-capital subsidiary which is invested by SAIC and professionally provides automotive logistics service.

The independent brand under SAIC is mainly Shanghai automobile. At present, it has two production bases, namely, Nanjing Pukou Base and Shanghai Nanhui Port. Lingang base is used as the storage base for vehicles produced by the Shanghai factory, the Nanjing Pukou Warehouse is used as the storage area for vehicles produced by the Nanjing factory. As a wholly-owned subsidiary of SAIC group, Agnelina Logistics undertakes the transportation business for products of SAIC at the two bases. At present, Agnelina Logistics can reach many city which have covered most parts of China.

For different transportation routes, Agnelina logistics will adopt different modes of transport.

At present, the two brands of SAIC have good reputation China. In recent years, sales volume is also 
growing at a steady status. Agnelina logistics provides good service for it.

\section{B. SWOT Method Analysis}

On the current situation which Agnelina logistics faces, application of SWOT analysis is made to reach fine analysis for providing basis for establishing scientific and reasonable transportation mode and route optimization.

\section{1) Advantage (Strength)}

a) Having good $R \& D$ ability and information basis.

With good R \& D ability and information basis the emerging logistics and modes can be used in a better way. So there will be more broad prospects for development.

b) Excellent brand reputation and stable customer resources

Its clients are almost all mainframe factories including Shanghai GM, Shanghai Volkswagen, Guangzhou Toyota, SAIC GM Wuling and BYD.

c) With smooth operation management and perfect operation process

In transportation and vehicle scheduling, Angelina company put forward the spot dispatch mode and headquarter dispatch mode, which effectively achieves the company's performance.

\section{d) Large scale and large market share}

Angelina logistics is one of the automobile suppliers with the largest business scale in provision of automobile logistics service.

2) Disadvantage (Weakness)

- Because such a large nationwide district lacks transferring stations and hubs, it is difficult to effectively integrate resources. When traffic accidents occurs in the way, complex process and increased vehicle none-goods transportation time rate, the process becomes complex and it takes a long term to transmit dispatch orders.

- No optimization and redesign is made on the present routes of Angelina logistics in the angle of the whole country, so the phenomena including returning to transport and detour transportation, which is not convenient for the enterprise.

3) Opportunities industry

a) Development potential of automobile logistics

\section{b) Constant Improving Technology}

Compared with other common logistics enterprise, informationization foundation of Angelina Logistics is good, and this will have more competitive advantage.

c) Favorable National Policies

In August 2011, the general office of the State Council issued "Opinion on Policies and Measures for Promoting Healthy Development of Logistics industry" (Guo Ban Fa ((2011) No. 38), It is known as the "nine items of national logistics policies" in the industry.

4) Threat

\section{a) Increased Transportation Costs}

There are many uncertain factors in development of logistics and transportation, which increases transportation costs. However, to simple rise prices is not possible. This will finally make Angelina's operating expenses increased which puts forward higher request on Angelina Logistics.

\section{b) Increased Competitive Pressures}

First, the third-party logistics industry changes rapidly, the huge pressure from he same industry in Hong Kong and Taiwan, and it is obviously this causes complexity for Angelina.

c) Significantly influenced by the automotive industry

Although as a rising industry, logistics has slow growth in the industry of automotive industry.

d) Adverse consequences of price war

The low level of price competition in the short term will not decay, which leads to a further declination of profits.

\section{STUDY ON OPTIMIZATION OF AGNELINA LOGISTICS TRANSPORTATION MODE AND ROUTES}

\section{A. Study of Agnelina Logistics Transportation}

\section{1) Characteristics of All Transportation Modes}

After the case is given, we should execute the to-order delivery through first choosing transportation modes and then choosing transportation routes.

The vehicle transportation plans of Angelina Logistics mostly take the mode of combining highway transportation and waterway transportation, through which the vehicles arriving the wharfs can reach the destination through choosing a long-distance transportation or choosing boat transportation.

What business concerns is always cost. The issue which the long-term strategic issues affecting the development of enterprises are how to make cost reduce. When a customer gives an order, transportation cost is what Angelina logistics firstly considers. The destinations of orders, what mode of transport and routes will produce influence on the time cost and economic cost of the logistics.

\section{2) Multi-modes Transportation}

Using a variety of modes of transportation, it provides comprehensive service at the lowest expenses and cost.

Compared with the conventional mode of transport, the present multi-mode transport can reduce the cost of logistics and transport, and it can realize optimization of the overall goal of goods transport.

\section{B. Using Mathematical Model to Solve Agnelina Logistics Transport Route Optimization Problem}

1) Analysis of Agnelina Logistics Transportation Problems

a) Choice of transport modes and reduction of transport costs

The current service provided by Agnelina Logistics to the customers are mostly point-to-point service.No matter which mode of transport is adopted, Agnelina's enterprise value is realization of the goal, namely, shortest, smallest cost and smallest capital and cost.

\section{b) Transportation Capacity can be Dispatched.}

In addition to how to take execution of SAIC whole vehicle transportation, Agnelina faces a challenge on different vehicle brands, and regional coordination. 
According to detailed requirements on orders, matching of vehicles is made on the surrounding vehicles.

Then the optimization of Agnelina logistics transportation thought is put forward

2) Optimization of Agnelina Logistics Transportation Line

The issue on logistics and transport is the study on transportation route optimization, but the logistics transportation route optimization is multi-objective optimization. So the key is how to choose the transportation lines, to reach the follows,

- Reducing the total transportation costs to the lowest,

- Trying to shorten the total transportation time.

On which route to take on the products transported to $\mathrm{A}$ and $\mathrm{B}$, According to the sending and receiving sites, the weighted graph can be drawn out, $\mathrm{G}=[\mathrm{V}, \mathrm{E}]$ (of which, $\mathrm{E}$ is the weight value, including the distance $\mathrm{S}$, city spot $\mathrm{V}$, freight expense $\mathrm{P}$, freight volume $\mathrm{Q}$ ).

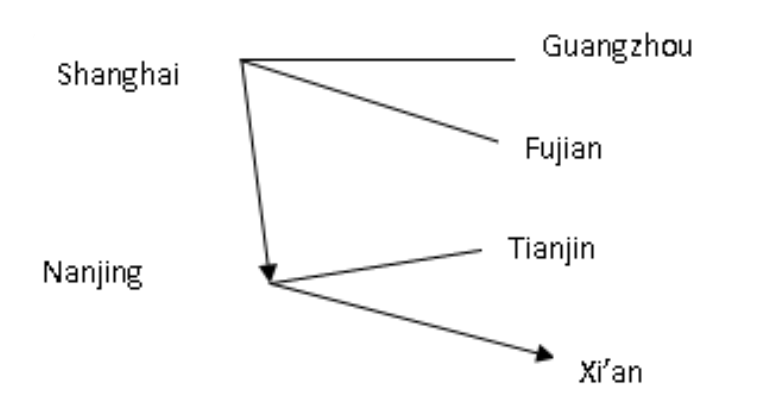

Figure 1. Weighted Graph

When the distance is the weight of the hypothesis condition, the shortest way can be calculated out with the $\mathrm{D}$ algorithm for the shortest path of the tree. When the time is now the weight of assumed conditions, the shortest time can be calculated out using the same method. Then, considering of many factors including distance and time is made, and rational routes are established according to the sales volume demanded in each city.

Simple problem-solving thinking, convenient construction model, Without considering the cases such as tolls and traffic jam, only with considering some representative cities, the optimization schemes for transport is as follows,

- If with highway transportation, the transportation

- expense function demanded by each vehicle to drive $\mathrm{x} \mathrm{km}$ required is as follows,

- If with sea (river) transportation, the transportation expense function demanded by each vehicle to drive $\mathrm{x} \mathrm{km}$ required is as follows:

$y=1.0 * a * x, x>0$ a) Optimization of Automobile Logistics and Transportation:

If in Nanjing, a quantity of B Roewe cars are ready to be removed to Zhengzhou, Ji'nan, Beijing, Tianjin and Shenyang, then Zhengzhou is set as a transferring station. Nanjing is established as P, and Zhengzhou, Ji'nan, Beijing, Tianjin and Shenyang are established respectively as A, B, C, D, E.

The distance relationship between the cities (according to the shortest routes between two cities) into tree form:

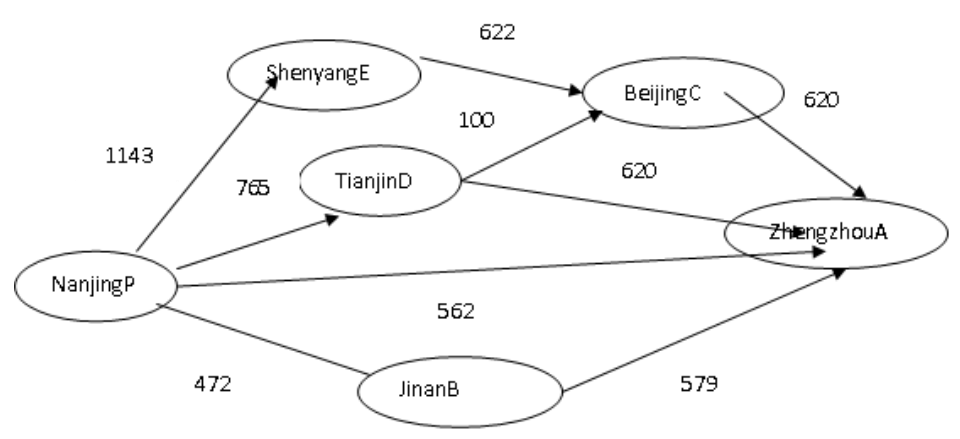

Figure 2. Five-Cities Tree Chart including Nanjing and Zhengzhou

According to the above chart:

We can directly know that the distance from Nanjing to Zhengzhou is the shortest distance. If the line is excluded, according to the Prim algorithm and Kruskal algorithm of the minimum tree, the distances from Nanjing to Zhengzhou for transportation are arranged as follows,

- $\quad P \rightarrow A$ a distance of $562 \mathrm{~km}$;

- $\quad P \rightarrow B \rightarrow A$ a distance of $1051 \mathrm{~km}$;

- $\quad P \rightarrow D \rightarrow A$ a distance of $1385 \mathrm{~km}$

- $\quad P \rightarrow C \rightarrow D \rightarrow A$ a distance of $1485 \mathrm{~km}$

- $\quad P \rightarrow E \rightarrow C \rightarrow A$ a distance of $2385 \mathrm{~km}$

Although the distance from Nanjing to Zhengzhou is the shortest, this does not stands for its saves most cost and time by taking goods from Nanjing directly to Zhengzhou. costs:

b) Optimization of vehicle logistics and transport

Distribution cost is the main logistics cost at the logistics transportation and distribution network center, And a large part of the distribution cost is transportation cost.

As the transport mileage, cost changes with the onmarket oil prices.

$$
y=\left\{\begin{array}{l}
2.0 * a * x, 0<x \leq 50 \\
1.7 * a * x, 50<x \leq 200 \\
1.5 * a * x, 200<x \leq 500 \\
1.3 * a * x, 500<x \leq 1000 \\
1.3 * a * x, x>1000
\end{array}\right.
$$

While the whole distribution center stresses meeting customers' requirement, logistics companies are required to spend the smallest cost. The network structure of the company can be constantly optimized with shortest time and shortest delivery distance. Vehicle transport routing 
problem can be described as $q_{i}(i=1,2, \mathrm{~L}, l)$, namely, the demand of the known task $i$, and $\sum_{i=1}^{l} q_{i} \leq Q$ met.

To use $m(1 \leq m \leq M)$ ( $M$ stands for the maximum allowable vehicle) vehicles to transport the goods in orders to the designated delivery point, the key is ways on how to make smallest fees meeting the transport requirement.

Assuming the initial stock volume in Nanjing or Shanghai $l_{0}$ ( Nanjing: $0 \leq l_{0} \leq 6000$; Shanghai : $0 \leq l_{0} \leq 12000$ ), the distance between cities is $s_{i j}$, and the fees between the logistics node cost on the distribution routes is $c_{i j}(i, j=1,2, \mathrm{~L}, n)$, Quantity in the trucks should not exceed the rated quantity in the operation course. $\min Z=\sum \sum c_{i j} *_{i j} * q_{i j}$ 。The objective function of the considered the transportation cost is $\min Z=\sum \sum c_{i j} *_{i j} * q_{i j}$. If the transport time is minimum, a target function model can be established.

Then, according to the calculated time consensus $t_{i j}=s_{i j} / v$, the time demanded by each transport route can be calculated. Here, $v$ can be the highway transportation speed, and it also can be the shipping speed, Comparison of calculation results is made. Then, according to the volume required by each city, the feasibility of integrated scheduling transportation can be considered.

To establish the best mathematical model on the above transportation optimization, we need to consider many realistic factors. If the limited conditions are in ideal status, there would be deviation from the actual. This model would not have great significance.

Above is the thought on optimization of Angelina logistics transportation modes, in which there are some deficiencies. Specifically, how to optimize cannot be made within a short term. We need to prepare to make long-term operation, always pay attention to dynamics of China's logistics industry. According to the actual situation, repeated presupposition, reasonable repeatedly debugging, testing, modification, debug, test running...should be made. It is a repeating process.

\section{CONCLUSION}

In the high-speed growing automobile industry, there are a lot of problems in the whole vehicle logistics industry. It is the most series that low logistics resource allocation efficiency and too-high non-product transportation cause high cost of logistics. The vehicle transportation cost of most of the vehicle logistics enterprises is 2-3 times that of developed countries in Europe and America, This is the main reason for the low return on assets of enterprises, The non-product transportation in vehicle logistics is the highest and it is from $37 \%$ to $49 \%$. The logistics cost in China is over $13 \%$. Strengthening cooperation within the industry 。 and deduce no-loading rate becomes the inevitable direction of China Automotive logistics.

\section{REFERENCE}

[1] Zhou Ying, Zhou Linfeng. On Choice of AHP Modes of Transport Logistics [J]. Technology and Market, 2010, (06): 34`35

[2] Xiao Jianhua, Fan Jiuwei and Wang Fei. Automobile Logistics Development Status, Problems and Countermeasures [J]. Port Logistics Technology and Application, 2012, (11): $42 ` 45$

[3] Tang Guosheng, Zhang Meizi and Tan Zhixiong. Study on Ji Logistics Network Operation and third-party Logistics Strategic Positioning of $[\mathrm{J}]$. Logistics Engineering and Management, 2013, (03)

[4] Agnelina Cup "of the Fourth National Student Logistics Design Competition (case six)

[5] Hu Xiaoxiao, SH Automobile Logistics Companies Optimization Analysis of [J]. Logistics Engineering and Management, 2012, (05): $60 \div 62$

[6] Huang Xiaoqing, Transportation Node Optimization Analysis of An Automobile Logistics Company with the Mixed Model [J] Jinxiu Forum, 2012, (12): 63

[7] Global Automotive Logistics - 2013 Report [J]. M2 Presswire , 2013

[8] Anonymous. Research and Markets; Global Automotive Logistics 2011 Report - Complex Challenges Ahead [J]. Technology \& Business Journal , 2011

TABLE I. ADVANTAGES OF MULTIMODAL TRANSPORT

\begin{tabular}{l|l}
\multicolumn{1}{c|}{ Advantages } & 1. multi-modes joint transportation with containers as units, this can operation efficiency; \\
of Multi-Modes & 2. "Zero distance" sales service, door-to-door transportation can be obtained through \\
Joint & implementation; \\
Transportation & 3 Reducing damage of products caused tin ex-packing and middle sections.
\end{tabular}

1) Multi-modes joint transportation business method takes the transportation method of a pay, a single order to end, a shipments, unified claiming for compensation, unified service, all-distance responsibility.

2) Choosing best transportation routes and organizing reasonable transportation.

Multimode transportation can save transportation costs and reduce transportation costs. 